Volume: 1, Issue: 1, March 2016, Pages: 6-7, DOI: http://dx.doi.org/10.19082/ah6

\title{
WOMEN'S BLOOD DONATION: ITS BARRIERS AND IMPACTS ON BLOOD SAFETY
}

\author{
Hamidreza Safabakhsh
}

Department of Education and Research, Khorasan-e-Razavi Blood Center, Mashhad, Iran

TYPE OF ARTICLE: MINI REVIEW

\begin{abstract}
One of the health needs of every society is the availability of blood and its products. Increasing development of medicine has resulted in increased medical interventions and surgeries. Therefore, the need for blood and its products has increased. This trend has led to worries of countries and challenges of blood transfusion centers to supply sufficient, safe blood. Voluntary blood donation is the main source of providing blood and its products, both of which are important to the health of patients who need blood. This brief paper deals with the importance of women's donations of blood.
\end{abstract}

KEYWORDS: Blood safety, Woman, Blood donor

\section{INTRODUCTION}

To make safe blood available and to assure sufficient quantities of blood for the present and the future, there must be continuous, voluntary donations of blood. Assuring the sufficiency of safe blood to meet the increasing demand in the future depends on continuous and voluntary, non-remunerated blood donation in each society $(1,2)$. Considering that women account for half of the population, increasing their participation in blood donation is one of the important strategies to supply new and increasing demands for blood in societies. Studies have shown that female blood donors have been more honest in answering physicians' questions concerning risky sexual behaviors, history of diseases, and medications they take. In fact, women are one of the safest blood resources available. Increasing blood donation indices of women could be a great step in social development and changes in false gender attitudes in society in addition to assisting the promotion of health in society and supplying the need for blood and its products. Therefore, to achieve these objectives, the effective communication of women with blood transfusion centers is a necessity $(2,3)$.

\section{BARRIERS OF WOMEN'S PARTICIPATION IN BLOOD DONATION AND SOLUTIONS TO PROMOTE THEIR PARTICIPATION}

In the three recent decades in Iran, with increased awareness and communication and changes in attitudes, women's social participation has increased as well. Among these changes are significant increases in their entering universities, NGOs, scientific associations, cooperatives, as well as participating in the Society for Protecting the Rights of the Child, in the Association for Women's Rights, in parent-teacher associations, in humanitarian activities, and in supporting the elderly and protecting the environment. Currently, $2.5 \%$ of the people voluntarily go to blood transfusion centers to donate blood, but more than $90 \%$ of those donors are males. Women's share in voluntary blood donation in Iran is less than 10\%. However, this participation reaches 45 to $55 \%$ in developed countries, such as America, Western Europe, and Oceania (2-4). According to a report published by the World Health Organization (WHO), only $30 \%$ of blood donation across the world is by females. However, in the aforementioned western countries females comprise over $40 \%$ of blood donors. Of the 100 countries mentioned in a report by WHO, 17 of the countries had female blood donors that contributed less than 10\% of the supply. According to the statistics of WHO, two billion people among the world's population of 6 billion people suffer from iron deficiency, and this is more common in females than in males. Some causes of anemia include nutritional deficiencies, bleeding, genetic disorders, and chronic diseases (5). Based on a study by the Iranian Blood Transfusion Organization Research Center on the Iranian female population between 17-65 years of age in the eight Provinces of Ardebil, Sistan, Baluchestan, Hormozgan, East Azerbaijan, Lorestan, Chaharmahal and Bakhtiari, Bushehr and Golestan, women's disinclination to donate blood was investigated. Cultural problems of Iranian

\section{Correspondence:}

Department of Education and Research, Khorasan-e-Razavi Blood Center, Mashhad, Iran.

E-mail: drsafabakhsh@yahoo.com

Received: January 04, 2015, Accepted: February 24, 2016, Published: March 2016

iThenticate screening: February 02, 2016, English editing: February 28, 2016, Quality control: March 04, 2016

(C) 2016 The Authors. This is an open access article under the terms of the Creative Commons Attribution-NonCommercialNoDerivs License, which permits use and distribution in any medium, provided the original work is properly cited, the use is non-commercial and no modifications or adaptations are made. 
women, including the fear of suffering from infectious diseases and anemia and their lack of knowledge about the demand of society for blood donations are among the common reasons of low blood donation among the female population. In addition, the small number of women who donate blood could be because of iron deficiency anemia (IDA), and consuming iron compounds in a given period could be effective in preventing anemia and lesser rejection of female donors (3). In a study conducted over a 10-year period in Iran in 1997, units of blood donated by women were $15 \%$ compared to $85 \%$ for men, and this ratio was $8 \%$ in women and $92 \%$ in men in 2008 (6). In most European countries, males and females donate blood at the same rate, except for Italy and Greece, where females account for 30\% of blood donors. In Spain, France, England, Finland, and the United States, women account for 46, 50,5355 , and over $40 \%$ of blood donors, respectively (4). Identifying demographic features, including gender, is significantly effective in selecting and maintaining policies that encourage people to donate blood and to do so routinely. Gender plays an important role in the incentives of blood donators in Europe in such a way that humanitarian incentives and assisting others are more prevalent in females and personal incentives and social pressure are more common among males. Blood donating reactions result in women's donating blood less regularly and repeatedly (2-4). Females are exempted from blood donation because of medical reasons, especially iron deficiency and low weight. Therefore, female donors should be controlled more carefully, and it should be emphasized to them that this is a temporary condition, not a basis for permanent rejection, so they can donate blood later (4). In one study concerning internal incentives, $60.5 \%$ of Iranian women were significantly higher than men (3). In addition, the decreased number of female donors who donate blood repeatedly could be because of iron deficiency, and, therefore, taking iron supplements for a given period of time could be effective in preventing anemia and reducing the number of females who are rejected as blood donors (4).

\section{CONCLUSIONS}

The community of women is regarded as safer population in terms of risky sexual behaviors in transfusion transmitted infections, and they account for half of the population. So, in countries with less participation of women in voluntary blood donation, blood transfusion centers must pay more attention to this population. The necessary and effective measures could include correcting women's negative attitudes toward donating blood.

\section{CONFLICT OF INTEREST:}

There is no conflict of interest to be declared.

\section{REFERENCES:}

1) Greinacher A, Fendrich K, Alpen U, Hoffmann W: Impact of demographic changes on the blood supply: Mecklenburg-West Pomerania as a model region for Europe. Transfusion 2007; 47:395-401. http://dx.doi.org/10.1111/j.1537-2995.2007.01129.x, PMid: 17319818

2) Steele WR, Schreiber GB, Guiltinan A, et al. The role of altruistic behavior, empathetic concern, and social responsibility motivation in blood donation behavior. Transfusion 2008; 48: 43-54. PMid: 17894795

3) Khadir M, Maghsudlu M, Gharehbaghian A, Danandeh E, Faghih H, Vafaiyan V, et al . The evaluation of the attitude of Iranian women towards blood donation. Sci J Blood Transfus Organ. 2004; 1 (1) :27-34

4) Marco Bani, Barbara Giussani. Gender differences in giving blood: a review of the literature. Blood Transfus 2010;8:278-287. PMid: 20967170m PMCid: PMC2957494

5) Gender distribution of blood donors, by country. Data reported by WHO Global Database on Blood Safety, 2008 (updated: June 2011)

6) Maghsudlu M, Nasizadeh S, Abolghasemi H, Ahmadyar S. Blood donation and donor recruitment in Iran from 1998 through 2007: ten years' experience. Transfusion. 2009 Nov;49(11):2346-51. http://dx.doi.org/10.1111/j.1537-2995.2009.02309.x, PMid: 19624488 